\title{
Primary, secondary or less frequent causes of immune thrombocytopenia: A case report
}

\author{
MINODORA ONISÂII ${ }^{1,2}$, ANA-MARIA VLĂDĂREANU ${ }^{1,2}$, IULIANA IORDAN $^{1,2}$, HORIA BUMBEA $^{1,2}$, \\ MIHAELA GĂMAN $^{1,2}$, CRISTINA CIUFU ${ }^{1,2}$, IRINA VOICAN ${ }^{1}$, DIANA CîȘLEANU ${ }^{1,2}$, DANIELA VASILE ${ }^{1,2}$, \\ CRISTINA MARINESCU ${ }^{1,2}$, ANCA NICOLESCU ${ }^{1}$, ANDREEA SPINNU $^{1,2}$, \\ RALUCA NISTOR $^{3,4}$ and ADRIAN ALEXANDRU ${ }^{5,6}$ \\ ${ }^{1}$ Hematology Clinic, Emergency University Hospital, 050098 Bucharest; ${ }^{2}$ Department of Hematology, \\ 'Carol Davila' University of Medicine and Pharmacy, 050474 Bucharest; ${ }^{3}$ Neurology Clinic, Emergency University Hospital, \\ 050098 Bucharest; ${ }^{4}$ Department of Neurology, 'Carol Davila' University of Medicine and Pharmacy, 050474 Bucharest; \\ ${ }^{5}$ Department of Plastic Reconstructive Surgery, Emergency University Hospital, 050098 Bucharest; \\ ${ }^{6}$ Department of Plastic Surgery, 'Carol Davila' University of Medicine and Pharmacy, 050474 Bucharest, Romania
}

Received March 1, 2021; Accepted March 31, 2021

DOI: $10.3892 / \mathrm{etm} .2021 .10530$

\begin{abstract}
Primary immune thrombocytopenia (ITP) is characterized by isolated low platelet count and it is a diagnosis of exclusion, contrasting to secondary ITP. Therefore, a positive diagnosis is difficult and requires extensive investigation. Some of the underlying conditions that are associated with ITP are lymphoproliferative disorders and infections, especially viral ones. In the present study, the case of a patient diagnosed with diffuse large B-cell lymphoma, who received chemotherapy and autologous hematopoietic stem cell transplantation is presented. After a complete remission of four years, the patient presented with sudden intense hemorrhagic syndrome and severely decreased platelet count. The most frequent causes of secondary ITP were excluded, including lymphoma relapse, and intravenous corticosteroids were started. However, shortly after hospital admission, the patient developed neuro-psychiatric anomalies, fever and pancytopenia, and West-Nile encephalitis was diagnosed. Although the initial development was favorable, he started to complain of progressive severe muscle weakness and eventually succumbed to infectious complications in the setting of prolonged hospitalization, corticotherapy, and immobilization.
\end{abstract}

\section{Introduction}

Thrombocytopenia is defined as a low number of platelets. There are multiple mechanisms and differential diagnosis

Correspondence to: Dr Mihaela Găman, Hematology Clinic, Emergency University Hospital, Splaiul Independentei 169, 050098 Bucharest, Romania

E-mail: mihaela_dervesteanu@yahoo.com

Key words: thrombocytopenia, lymphoma, West-Nile virus, encephalitis, corticotherapy includes: artifactual thrombocytopenia, accelerated platelet destruction (intra- or extra-corpuscular anomalies), deficient production (bone marrow failure, disordered proliferation or thrombopoietin deficiency), and abnormal distribution (disorders associated with splenomegaly or dilution in massive transfusions) (1).

Immune thrombocytopenia (ITP) is an autoimmune disorder characterized by immune-mediated destruction and impaired production of platelets, with isolated thrombocytopenia. Primary ITP remains a diagnosis of exclusion, in contrast to ITP which is secondary to various conditions: infections are among common causes, mostly viral ones (hepatitis C, HIV infection, CMV, EBV) (2).

Some of the many underlying disorders that are associated with immune thrombocytopenia are also lymphoproliferative disorders. The prevalence of ITP in non-Hodgkin's lymphoma patients is lower compared to autoimmune hemolytic anemia, occurring in only up to $1.8 \%$ of cases (3).

In the present study, the case of a patient with diffuse large B-cell lymphoma evolving from grade 3 a follicular lymphoma, who maintained a complete response for 4-years, and then presented with severe isolated thrombocytopenia, is reported.

\section{Case presentation}

Ethics approval for the study was obtained from the Emergency University Hospital, Bucharest, Romania. The patient included in the study provided written informed consent.

The 62-year-old male was admitted to the Hematology Clinic with generalized purpura and atraumatic ecchymoses. The patient had been diagnosed 5 years prior to this presentation with diffuse large B-cell lymphoma evolving from grade 3 a follicular lymphoma. He was treated with chemotherapy (8 R-CHOP protocols) with partial response, followed by high-dose chemotherapy and autologous hematopoietic stem cell transplantation, with a complete response, and was stable for the previous 4 years. The patient also had a 
history of poorly controlled diabetes mellitus type 2, arterial hypertension, and depressive disorder. The lymphoma and its treatment, and also the poorly controlled diabetes contributed to the immune deficiency of our patient.

The patient reported that purpura and ecchymoses had appeared two days prior to presentation. He denied use of new medication, including vaccines, recent international travels, weight loss, fever, or other symptoms. The physical examination was normal except for the cutaneous hemorrhagic syndrome.

Investigations at admission revealed severe thrombocytopenia $\left(\mathrm{PLT}=3 \times 10^{9} / 1\right)$, normal white blood cell count and hemoglobin, without any significant changes in hepatic and renal function tests, electrolyte levels, or coagulation. Screening tests for infectious diseases (HBV, HCV, HIV, Helicobacter pylori and stool antigen test), tumors $(\alpha$-fetoprotein, carcinoembryonic antigen, prostate-specific antigen, CA19-9, imaging studies), and immune-mediated disorders (C3 complement, serum cryoglobulins, rheumatoid factor, antinuclear antibodies, anticardiolipin antibodies, lupus anticoagulant) were negative. No pathogenic bacteria were found in blood cultures. Tests for CMV infection and thrombopoietin levels were not available in our center. The bone marrow biopsy was not noteworthy, normal and active megakaryocytes were observed, and negative for malignant lymphoid infiltration. The CT scan of the thorax, abdomen, and pelvis showed no other modifications compared to the previous examinations. Previously, the patient was periodically examined by a CT scan every 6 months. He had small $(<1 \mathrm{~cm})$ metabolically inactive mediastinal lymphadenopathies, unchanged for 4 years.

A diagnosis of primary immune thrombocytopenia was established and treatment was started with intravenous corticosteroids. The platelet count remained low for about 14 days, and then began to progressively increase up to normal values on day 18 of treatment (Fig. 1).

Since day 11-12, progressive modifications of the patient's mental status, including poor eye-contact, inattention to personal appearance, sad mood, monosyllabic speech with long pauses, negative self-view and negative view of the future, hypersomnia, and appetite loss, was observed. Considering his history of depressive disorder, which may have been aggravated under corticosteroids, prolonged hospitalization, and the initial lack of response, the psychiatrist recommended treatment with anxiolytics and antidepressants.

On day 16, the patient developed two episodes of low fever; blood cultures were collected, and empirical broad-spectrum antibiotics were started.

On day 18 of treatment, the patient's condition suddenly worsened: he became noncompliant, agitated, aphasic, dyspneic with low blood oxygen saturation $(86 \%)$, later followed by fever $\left(39^{\circ} \mathrm{C}\right)$. Laboratory findings revealed leukocytosis with neutrophilia and lymphopenia (which had been present for a few days, possibly also due to the corticosteroid treatment), followed by leukopenia, moderate anemia (without any bleeding, also observed progressively in the previous days), slightly increased aminotransferase and indirect bilirubin, severe hyponatremia, normal C-reactive protein and coagulation. Chest $\mathrm{X}$-ray was negative for infection.
Cerebral-computed tomography was normal, and repeated lumbar punctures revealed hyperglycorrhachia, normal protein and albumin levels; CSF cellularity was low (21 elements $/ \mu 1$ ). Magnetic resonance imaging could not be performed at that time due to the presence of a metallic object in the patient's thumb.

We started correction of hyponatremia, but without significant improvements in symptomatology, corticosteroids (de-escalation of doses), and prophylactic broad-spectrum antibiotics. Blood cultures proved to be negative for aerobic and anaerobic bacteria and fungi.

Given the neurological symptoms and the fever, we considered that the most likely cause was infection. As the patient was admitted to the hospital in the fall and Romania is an endemic area, we considered it opportune to perform serologic testing for West-Nile virus; serum immunoglobulin $\mathrm{M}$ antibodies in the blood and cerebrospinal fluid were positive. The final diagnosis was West-Nile encephalitis. CBC also showed transient pancytopenia for $72 \mathrm{~h}$.

Antibiotics were stopped and corticosteroids were continued as per the Infectious Disease specialist's recommendation. The clinical evolution was favorable, although the patient developed progressive muscle weakness. He became compliant, and the hematological and biochemical tests improved.

After stabilization of clinical and biological parameters, the patient was transferred to the Department of Neurology for additional investigations regarding his muscle weakness, and for neurological rehabilitation. Although there was improvement, a week after admission, the patient's state worsened with fever, dyspnea, and productive cough. Thoracic imaging was suggestive for bronchopneumonia; aerobic and anaerobic blood cultures were positive for Klebsiella pneumoniae. The patient developed septic shock in spite of broad spectrum-specific antibiotherapy and intensive care, and subsequent multiple organ failure. He died $72 \mathrm{~h}$ later.

\section{Discussion}

West-Nile virus is a member of the Flaviviridae family transmitted mostly by mosquito bite, but also through blood transfusions, organ transplantation, breastfeeding, or percutaneous inoculation. The usual incubation period is 3-14 days (4). Most of the infected patients $(75 \%)$ are asymptomatic, while the remaining patients may experience influenza-like symptoms (25\%), and only a minority develop neuroinvasive disease $(<1 \%)(5,6)$. Patient risk-factors for developing central nervous system involvement are advanced age, a history of cardiovascular disease, chronic renal disease, hepatitis $\mathrm{C}$ virus infection, and immunosuppression (7). Furthermore, a study reported that defects in draining lymph nodes result in increased susceptibility for West-Nile infection (8).

It is widely known that viral infections are associated with various degrees of thrombocytopenia. Several cases of West-Nile-related thrombocytopenia have been reported, but the severe ones have been quite rare (9-11). The underlying mechanisms are not yet completely understood; studies regarding another virus from the same family (Dengue virus) suggest complex pathogenesis of thrombocytopenia, including the formation of platelet-leukocyte aggregates, sequestration 


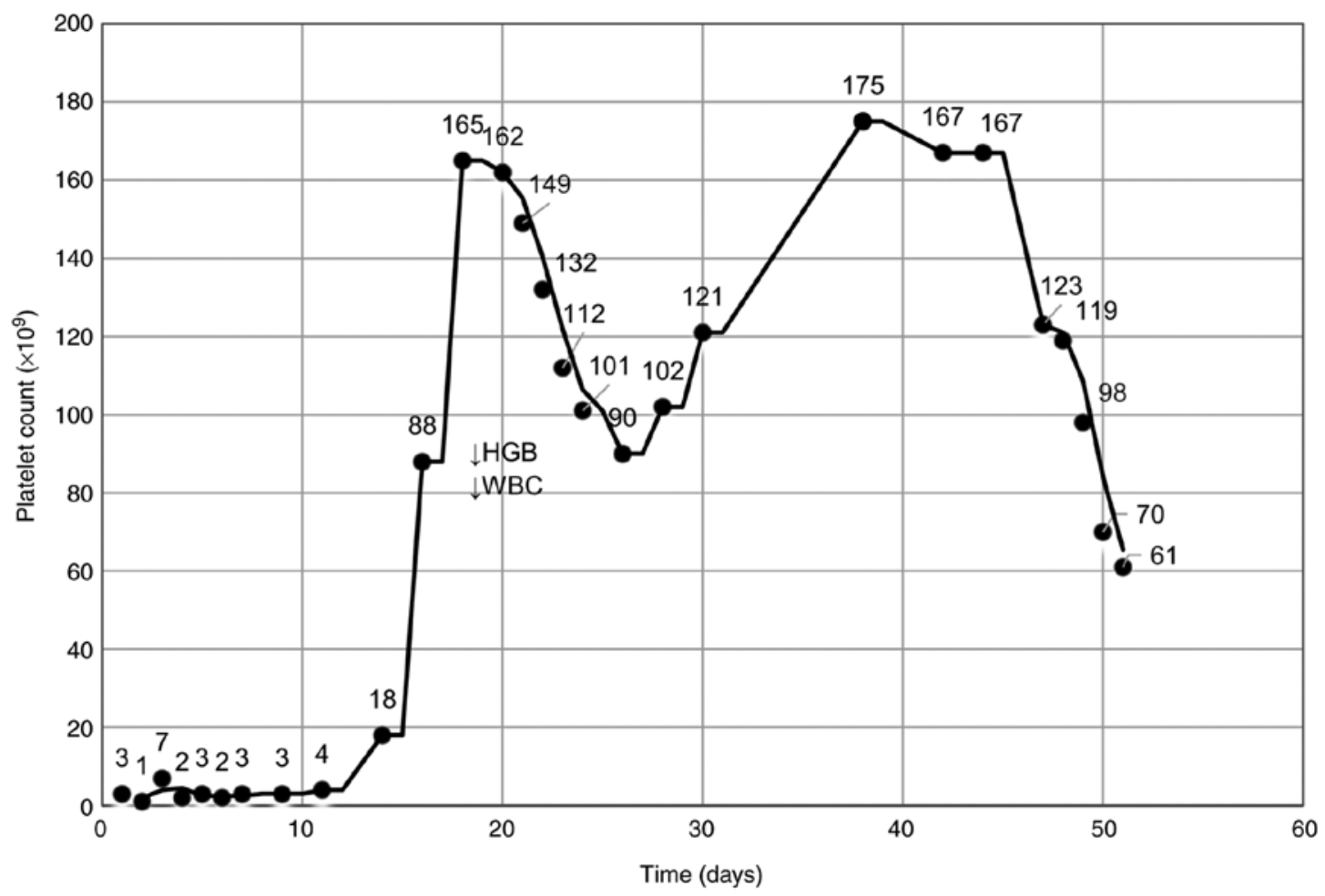

Figure 1. Evolution of platelet count. The platelet count remained low for about 14 days, and then began to progressively increase up to normal values on day 18 of treatment. HGB, hemoglobin, WBC, white blood cell count.

in the reticuloendothelial system, followed by phagocytosis, production of cross-reactive antibodies for platelet antigens, and suppression of hematopoiesis (12).

Determining the cause of thrombocytopenia can be challenging. Underlying diseases that are associated with thrombocytopenia include lymphoproliferative disorders (e.g., chronic lymphocytic leukemia, non-Hodgkin's lymphoma, and Hodgkin lymphoma), bone-marrow diseases (e.g., myelodysplastic syndromes, leukemias, metastatic disease), post-transplantation (allogeneic or autologous stem cell transplantation), microangiopathic processes (thrombotic thrombocytopenic purpura, hemolytic uremic syndrome), infectious diseases (e.g., Helicobacter pylori, hepatitis C, HIV infection, CMV, EBV), autoimmune disorders (e.g., systemic lupus erythematosus), liver diseases (cirrhosis, portal hypertension), splenomegaly, and drugs (2,13-20). Failure in demonstrating the presence of an underlying pathology conducts towards the diagnosis of primary immune thrombocytopenia.

We performed an extensive search for secondary ITP. At presentation, from anamnesis and physical examination, no underlying condition or risk factors were identified: No fever or other signs of infection, no lymphadenopathy or hepatosplenomegaly, and the patient denied exposure to new medication, vaccination or other toxins. Thrombocytopenia secondary to a microangiopathic process (thrombotic thrombocytopenic purpura or hemolytic uremic syndrome) was also excluded: absence of renal, neurological, gastrointestinal or other typical symptoms, lack of anemia, reticulocytosis or schistocytes, and otherwise normal organ functions (15).

Based on laboratory and imaging results, the following conditions seemed improbable: infectious diseases (negative for $\mathrm{HIV}, \mathrm{HCV}, \mathrm{HBV}$, Helicobacter pylori), autoimmune disorders (normal values for C3 complement, serum cryoglobulins, rheumatoid factor, autoimmune panel), and solid tumors (normal values for the tested tumoral markers, normal CT scan). Testing for CMV was not available in our center.

In our case, given the prior medical history of non-Hodgkin's lymphoma (NHL), we considered vital to exclude a relapse or a secondary malignancy, both hematological and solid.

Lymphoproliferative disorders are occasionally associated with hematological autoimmune phenomena, mostly autoimmune anemia, but also ITP, the latest occurring in $0-1.8 \%$ of patients with NHL (3). Several case-reports and meta-analyses described cases of ITP occurring prior or synchronous to the diagnosis of lymphoma, or after the completion of treatment (3,21-27). In addition, immune thrombocytopenia occurring after autologous stem cell transplantation has been mentioned, with an onset period of 1-31 months (3).

We found no evidence suggestive for relapsed lymphoma or secondary malignancy, both solid and hematological (e.g., acute leukemia, myelodysplastic syndrome): no clinical signs, no adenopathy or hepatosplenomegaly, no weight loss or fever or night sweats, no other CBC anomalies, normocellular bone marrow, without malignant lymphoid infiltration, and unremarkable CT scan.

After the exclusion of all the previously mentioned causes of thrombocytopenia, we established the diagnosis of ITP and started intravenous corticosteroid treatment. The platelet counts gradually increased to normal values, while the neutrophil count began to rise, and the hemoglobin level to decrease (Table I). Furthermore, the patient's condition worsened and he developed first psychiatric and then neurological symptoms. Considering the clinical evolution, we performed several 
Table I. Laboratory findings.

\begin{tabular}{|c|c|c|c|c|c|}
\hline $\begin{array}{l}\text { Parameter } \\
\text { (normal value) }\end{array}$ & $\begin{array}{l}\text { Days 1-2 Admission } \\
\text { in the Hematology Clinic }\end{array}$ & $\begin{array}{c}\text { Days } 18-19 \\
\text { Onset of neurological } \\
\text { symptoms }\end{array}$ & Day 23 & $\begin{array}{l}\text { Day } 38 \\
\text { Admission in the } \\
\text { Neurology Clinic }\end{array}$ & $\begin{array}{c}\text { Day } 51 \\
\text { Deceased }\end{array}$ \\
\hline \multicolumn{6}{|l|}{$\mathrm{CBC}$} \\
\hline WBC (3.6-10.2x109/1) & $10.5 \times 10^{9} / 1$ & $17.4 \times 10^{9} / 1$ & $2.5 \times 10^{9} / 1$ & $8.3 \times 10^{9} / 1$ & $2.7 \times 10^{9} / 1$ \\
\hline Neutrophils (1.7-7.6x109/1) & $6.2 \times 10^{9} / 1$ & $15.3 \times 10^{9} / 1$ & $1.7 \times 10^{9} / 1$ & $6.6 \times 10^{9} / 1$ & $2.0 \times 10^{9} / 1$ \\
\hline Lymphocytes $\left(1.0-3.2 \times 10^{9} / 1\right)$ & $3.2 \times 10^{9} / 1$ & $1.4 \times 10^{9} / 1$ & $0.7 \times 10^{9} / 1$ & $1.5 \times 10^{9} / 1$ & $0.6 \times 10^{9} / 1$ \\
\hline HGB (12.5-16.3 g/dl) & $13.2 \mathrm{~g} / \mathrm{dl}$ & $8.2 \mathrm{~g} / \mathrm{dl}$ & $7.5 \mathrm{~g} / \mathrm{dl}$ & $10.9 \mathrm{~g} / \mathrm{dl}$ & $9.7 \mathrm{~g} / \mathrm{dl}$ \\
\hline PLT (150-400x 109/1) & $3 \times 10^{9} / 1$ & $165 \times 10^{9} / 1$ & $112 \times 10^{9} / 1$ & $175 \times 10^{9} / 1$ & $61 \times 10^{9} / 1$ \\
\hline \multicolumn{6}{|l|}{ Biochemistry } \\
\hline ALT (3-65 U/1) & $47 \mathrm{U} / 1$ & $87 \mathrm{U} / 1$ & $60 \mathrm{U} / 1$ & $86 \mathrm{U} / 1$ & $592 \mathrm{U} / 1$ \\
\hline AST (2-40 U/1) & $31 \mathrm{U} / 1$ & $38 \mathrm{U} / 1$ & $28 \mathrm{U} / 1$ & $26 \mathrm{U} / 1$ & $853 \mathrm{U} / 1$ \\
\hline Total bilirubin $(0-1.2 \mathrm{mg} / \mathrm{dl})$ & $0.66 \mathrm{mg} / \mathrm{dl}$ & $1.16 \mathrm{mg} / \mathrm{dl}$ & $0.8 \mathrm{mg} / \mathrm{dl}$ & $0.64 \mathrm{mg} / \mathrm{dl}$ & $0.88 \mathrm{mg} / \mathrm{dl}$ \\
\hline Direct bilirubin $(0-0.3 \mathrm{mg} / \mathrm{dl})$ & $0.23 \mathrm{mg} / \mathrm{dl}$ & $0.45 \mathrm{mg} / \mathrm{dl}$ & $0.3 \mathrm{mg} / \mathrm{dl}$ & $0.18 \mathrm{mg} / \mathrm{dl}$ & $0.13 \mathrm{mg} / \mathrm{dl}$ \\
\hline Sodium (135-150 mmol/l) & $136 \mathrm{mmol} / \mathrm{l}$ & $123 \mathrm{mmol} / 1$ & $136 \mathrm{mmol} / \mathrm{l}$ & $127 \mathrm{mmol} / \mathrm{l}$ & $138 \mathrm{mmol} / \mathrm{dl}$ \\
\hline LDH (125-220 U/1) & $204 \mathrm{U} / 1$ & - & $372 \mathrm{U} / 1$ & $245 \mathrm{U} / 1$ & - \\
\hline Urea $(12-45 \mathrm{mg} / \mathrm{dl})$ & $33 \mathrm{mg} / \mathrm{dl}$ & $50 \mathrm{mg} / \mathrm{dl}$ & $66 \mathrm{mg} / \mathrm{dl}$ & $44 \mathrm{mg} / \mathrm{dl}$ & $128 \mathrm{mg} / \mathrm{dl}$ \\
\hline Creatinine $(0.5-1.5 \mathrm{mg} / \mathrm{dl})$ & $1.41 \mathrm{mg} / \mathrm{dl}$ & $1.27 \mathrm{mg} / \mathrm{dl}$ & $1.16 \mathrm{mg} / \mathrm{dl}$ & $1.07 \mathrm{mg} / \mathrm{dl}$ & $2.27 \mathrm{mg} / \mathrm{dl}$ \\
\hline $\mathrm{CRP}(0-5 \mathrm{mg} / \mathrm{l})$ & $17.77 \mathrm{mg} / \mathrm{l}$ & $0.5 \mathrm{mg} / \mathrm{l}$ & $5 \mathrm{mg} / \mathrm{l}$ & $11.38 \mathrm{mg} / \mathrm{l}$ & - \\
\hline \multicolumn{6}{|l|}{ Coagulation } \\
\hline PT (9-13.5 sec) & $11.3 \mathrm{sec}$ & $11.7 \mathrm{sec}$ & $11.7 \mathrm{sec}$ & $11.1 \mathrm{sec}$ & $17.7 \mathrm{sec}$ \\
\hline APTT (22-36 sec) & $26.8 \mathrm{sec}$ & $24.8 \mathrm{sec}$ & $24.9 \mathrm{sec}$ & $24.1 \mathrm{sec}$ & $66.0 \mathrm{sec}$ \\
\hline Fibrinogen $(238-498 \mathrm{mg} / \mathrm{dl})$ & $369.33 \mathrm{mg} / \mathrm{dl}$ & $368 \mathrm{mg} / \mathrm{dl}$ & $280 \mathrm{mg} / \mathrm{dl}$ & $291 \mathrm{mg} / \mathrm{dl}$ & $385 \mathrm{mg} / \mathrm{dl}$ \\
\hline \multicolumn{6}{|l|}{ CSF exam } \\
\hline Glucose $(40-70 \mathrm{mg} / \mathrm{dl})$ & - & $82 \mathrm{mg} / \mathrm{dl}$ & $110 \mathrm{mg} / \mathrm{dl}$ & $97 \mathrm{mg} / \mathrm{dl}$ & - \\
\hline $\mathrm{CSF} /$ serum glucose ratio & - & 0.68 & 0.81 & 0.94 & - \\
\hline Protein $(15-45 \mathrm{mg} / \mathrm{dl})$ & - & $31.1 \mathrm{mg} / \mathrm{dl}$ & $23.6 \mathrm{mg} / \mathrm{dl}$ & $65.4 \mathrm{mg} / \mathrm{dl}$ & - \\
\hline Albumin $(5-20 \mathrm{mg} / \mathrm{dl})$ & - & - & $14.5 \mathrm{mg} / \mathrm{dl}$ & $38.7 \mathrm{mg} / \mathrm{dl}$ & - \\
\hline Nucleated elements & - & $21 / \mathrm{mm}^{3}$ & $5 / \mathrm{mm}^{3}$ & $6 / \mathrm{mm}^{3}$ & - \\
\hline Erythrocytes & - & $224 / \mathrm{mm}^{3}$ & $29 / \mathrm{mm}^{3}$ & $74 / \mathrm{mm}^{3}$ & - \\
\hline CSF-WNV IgM $(<0.8)$ & - & 6.27-Positive & - & - & - \\
\hline Serum-WNV IgM $(<0.8)$ & - & 8.24-Positive & - & - & - \\
\hline
\end{tabular}

CBC, complete blood count; WBC, white blood cells; RBC, red blood cells; PLT, platelets count; ALT, alanine aminotransferase; AST, aspartate aminotransferase; LDH, lactate dehydrogenase; PT, prothrombin time; APTT, activated partial thromboplastin time; CSF, cerebrospinal fluid; WNV, West-Nile virus.

investigations that conducted to the unexpected diagnosis of West-Nile encephalitis.

Regarding our patient, we evaluated two hypotheses. First, considering the onset of neurological symptoms at about 18 days since admission, one might think that the patient presented with primary immune thrombocytopenia and developed West-Nile infection while hospitalized. This hypothesis seems improbable. Furthermore, no other patients in the hospital experienced similar symptoms or were diagnosed with West-Nile virus infection in that period, although there is a high number of immunodeficient patients in our care.

It is more attractive to think that the patient developed immune thrombocytopenia secondary to West-Nile infection. He was asymptomatic at presentation, but he already had a degree of immunodeficiency (history of lymphoma treated with chemotherapy, followed by autologous stem cell transplantation) supplementary aggravated by corticotherapy, which could be a risk factor for the development of neuroinvasive disease. The downside of this hypothesis is related to the rarity of severe thrombocytopenia in West-Nile-infected patients and to the long period of time between onset of thrombocytopenia and neurological impairment. Concerning this point, we would like to mention the case of a patient with West-Nile infection who first developed severe thrombocytopenia and then symptoms, including high fever, generalized weakness, and altered mental status (11). Furthermore, neurological impairment can have a delayed onset due to delayed neuroinvasion (28). Moreover, our patient developed psychiatric symptoms at about 11-12 days after admission (within cited incubation period), followed by severe neurological abnormalities at about 18 days. 
Therefore, we reason that the patient presented immune thrombocytopenia triggered by exposure to West-Nile virus. We argue that the viral infection was not symptomatic at admission, as it generally is, but later became so, due to immunodeficiency induced by intense corticotherapy.

The clinical evolution of patients with West-Nile neuroinvasive disease is variable. Some may develop long-term neurological sequelae, including muscle weakness, myalgia, fatigue, memory loss, and depression $(5,7)$.

In general, the prognosis in West-Nile infection is favorable, except for the elderly and patients with multiple medical complications who have a poorer prognosis. Biological predictors of fatal outcome are C-reactive protein $>100 \mathrm{mg} / \mathrm{l}, \mathrm{CSF}$ protein $>100 \mathrm{mg} / \mathrm{dl}$, and West-Nile encephalitis (9).

Concerning our patient, he had a history of immunosuppression due to lymphoma, chemotherapy and autologous stem cell transplantation, and especially recent steroid treatment, as possible risk factors for developing a more severe form of West-Nile infection. He also had multiple comorbidities, such as poorly controlled diabetes mellitus type 2 , arterial hypertension, and depressive disorder. He did not have any of the previously mentioned biological predictors of fatal outcome, but he did in fact have an unfavorable progression. However, the direct cause of death was not encephalitis per se, but further complications. The patient had multiple risk factors for developing severe infections, such as prolonged hospitalization in multiple clinics (almost two months), prolonged corticotherapy (for immune thrombocytopenia and West-Nile encephalitis) and antibiotherapy, and immobilization secondary to neurological complications.

Thrombocytopenia is known to be associated with numerous disorders, therefore determining the cause is a major challenge. A careful physical examination, a complete medical history review, and a laboratory investigation can orientate towards the etiology.

Regarding our case, the etiology of thrombocytopenia remains incompletely clarified. Out of the many possible causes, although uncommon, the apparent etiology would be the West-Nile virus, which most likely triggered severe immune thrombocytopenia. The viral infection was initially asymptomatic, but shortly thereafter induced neuroinvasive disease which eventually became lethal by secondary complications.

Therefore, we recommend considering West-Nile infection as a potential etiology of thrombocytopenia, especially in endemic regions during West Nile activity season and for cases where more common causes have been excluded.

\section{Acknowledgements}

Not applicable.

\section{Funding}

No funding was received.

\section{Availability of data and materials}

All data generated or analyzed during this study are included in this published article.

\section{Authors' contributions}

Conceptualization was done by $\mathrm{MO}, \mathrm{AMV}, \mathrm{HB}, \mathrm{MG}$ according to ICMJE guidelines. Authenticity of all the raw data was assessed by MO, AMV, MG, AS, AA. Methodology was established by MO, AMV, II, HB, MG, CC, IV, DC, DV, CM, AN, AS, RN, AA. Validation was done by MO, AMV, HB, IV, DC. MO, II, MG, IV, DC performed the formal analysis. Investigation was performed by MO, AMV, II, HB, MG, CC, IV, DC, DV, CM, AN, AS, RN, and AA. Resources were established by MO, II, CC, IV, DC, DV, CM, AN, AS. Data curation was carried out by MO, CC, DV, AS, AA. Writing and original draft preparation was done by MO, II, CC, IV, DC, DV, CM, AN, AS. Visualization was accomplished by MO, AMV, HB, MG, RN, AA. MO, AMV, MG, IV, DC, AA supervised the project. Project Administrators were MO, AMV. All authors have read and agreed to the published version of the manuscript.

\section{Ethics approval and consent to participate}

Ethics approval for the study was obtained from the Emergency University Hospital Bucharest.

\section{Patient consent for publication}

The patient signed the informed consent.

\section{Competing interests}

The authors declare that they have no competing interests.

\section{References}

1. Greer JP, Rodgers GM, Glader B, Arber DA, Means RT, List AF, Appelbaum FR, Dispenzieri A and Fehninger TA: Wintrobe's Clinical Hematology: Fourteenth edition. Philadelphia, PA. Wolters Kluwer, 1069-1095, 2019.

2. Onisâi M, Vlădăreanu AM, Spînu $A$, Găman $M$ and Bumbea $H$ : Idiopathic thrombocytopenic purpura (ITP)-new era for an old disease. Rom J Intern Med 57: 273-283, 2019.

3. Hauswirth AW, Skrabs C, Schutzinger C, Raderer M, Chott A, Valent P, Lechner K and Jager U: Autoimmune thrombocytopenia in non-Hodgkin's lymphomas. Haematologica 93: 447-450, 2008.

4. Rudolph KE,Lessler J, Moloney RM, Kmush B and Cummings DA: Incubation periods of mosquito-borne viral infections: A systematic review. Am J Trop Med Hyg 90: 882-891, 2014.

5. Greco M, Cofano P and Lobreglio G: Seropositivity for west Nile virus antibodies in patients affected by myastenia gravis. J Clin Med Res 8: 196-201, 2016.

6. Ferrarini I, Rigo A, Gandini A and Vinante F: West Nile virus encephalitis in haematological setting: Report of two cases and a brief review of the literature. Mediterr J Hematol Infect Dis 11: e2019033, 2019.

7. Montgomery RR and Murray KO: Risk factors for West Nile virus infection and disease in populations and individuals. Expert Rev Anti Infect Ther 13: 317-325, 2015.

8. Richner JM, Gmyrek GB, Govero J, Tu Y, van der Windt GJ, Metcalf TU, Haddad EK, Textor J, Miller MJ and Diamond MS: Age-dependent cell trafficking defects in draining lymph nodes impair adaptive immunity and control of west Nile virus infection. PLoS Pathog 11: e1005027, 2015.

9. Urošević A, Dulović O, Milošević B, Maksić N, Popović N, Milošević I, Delić D, Jevtović D, Poluga J, Jordović J, et al: The importance of haematological and biochemical findings in patients with West Nile virus neuroinvasive disease. J Med Biochem 35: 451-457, 2016.

10. Uç D, Çelik T, Gönen D, Sucu A, Celiloglu C, Tolunay O and Celik U: A factor that should raise awareness in the practice of pediatric medicine: West Nile virus. J Pediatr Inf 12: e70-e72, 2018. 
11. Armstrong WS, Bashour CA, Smedira NG, Heupler FA, Haeltge GA, Mawhorter SD, Sudheendra V and Gordon SM: A case of fatal west Nile virus meningoencephalitis associated with receipt of blood transfusions after open heart surgery. Ann Thorac Surg 76: 605-607, 2003.

12. Hottz ED, Bozza FA and Bozza PT: Platelets in immune response to virus and immunopathology of viral infections. Front Med 5: $121,2018$.

13. Cooper $\mathrm{N}$ and Bussel $\mathrm{J}$ : The pathogenesis of immune thrombocytopenia. Br J Haematol 133: 364-374, 2006.

14. Cines DB, Bussel J, Liebman HA and Luning Prak ET: The ITP syndrome: Pathogenesis and clinical diversity. Blood 113: 6511-6521, 2009.

15. George JN: How I treat patients with thrombocytopenic purpura: 2010. Blood 116: 4060-4069, 2010.

16. Voican I, Onisâi M, Nicolescu A, Vlădăreanu AM and Vlădăreanu R: Heparin induced thrombocytopenia: A review. Farmacia 60: 773-784, 2012.

17. Onisâi M, Vlădăreanu AM, Delcea $C$, Ciorăscu M, Bumbea $H$, Nicolescu A, Voican I, Filipescu A, Rotaru O and Vlădăreanu R Perinatal outcome for pregnancies complicated with thrombocytopenia. J Matern Fetal Neonatal Med 25: 1622-1626, 2012.

18. Brooks WH: Viral impact in autoimmune diseases: Expanding the 'X chromosome-nucleolus nexus' hypothesis. Front Immunol 8: $1657,2017$.

19. Găman M, Vlădăreanu AM, Dobrea C, Onisâi M, Marinescu C, Voican I, Vasile D, Bumbea H and Cîșleanu D: A challenging case of Kikuchi-Fujimoto disease associated with systemic lupus erythematosus and review of the literature. Case Rep Hematol 2018: 1791627, 2018.

20. Provan D, Arnold DM, Bussel JB, Chong BH, Cooper N, Gernsheimer T, Ghanima W, Godeanu B, Gonzalezz-Lopez TJ, Grainger J, et al: Updated international consensus report on the investigation and management of primary immune thrombocy topenia. Blood Adv 22: 3780-3817, 2019.
21. Ono K, Onishi Y, Kobayashi M, Ichikawa S, Hatta S, Watanabe S, Okitsu Y, Fukuhara N, Ichinohasama R and Harigae H: Successful treatment of aggressive mature B-cell lymphoma mimicking immune thrombocytopenic purpura. Intern Med 57: 2573-2579, 2018.

22. Poponea N, Suede M and Muhsim Christi M: Idiopathic thrombocytopenia purpura masking Hodgkin disease: A paraneoplastic syndrome or simply a mere association? Case Rep Oncol 10: 1116-1120, 2017.

23. Park SY, Kim S, Kim ES, Choi SU, Hyun HJ, Ahn JY, Lee JH, Ryu SH, Park JH, Park JH, et al: A case of Non-Hodgkin's lymphoma in patient with Coombs' negative hemolytic Anemia and idiopathic thrombocytopenic purpura. Cancer Res Treat 44: 69-72, 2012.

24. Takahashi T, Maruyama Y, Saitoh M, Itoh H, Yosimoto M, Tsujisaki $M$ and Nakayama M: Synchronous occurrence of diffuse large B-cell lymphoma of the duodenum and gastrointestinal stromal tumor of the Ileum in a patient with immune thrombocytopenic purpura. Intern Med 55: 2951-2956, 2016.

25. Uchiyama M, Sato K and Ikeda T: Diffuse large B-cell lymphoma complicated with autoimmune thrombocytopenia. Intern Med 50: 1215-1218, 2011.

26. Watanabe T, Kurihara H, Magarisawa S, Shimoda S, Yoshida K and Ishiuchi S: Resolution of immune thrombocytopenic purpura associated with extranodal B-cell lymphoma of the petroclival region after radiotherapy. Surg Neurol Int 1: 76, 2010.

27. Karami H, Naderisorski M, Ghasemi M and Sakhaei SM: Immune thrombocytopenia as a primary sign of relapse in Hodgkin lymphoma: A case report. IJBC 11: 72-74, 2019.

28. Sejvar JJ, Davis LE, Szabados E and Jackson AC: Delayed-onset and recurrent limb weakness associated with West Nile virus infection. J Neurovirol 16: 93-100, 2010. 